\title{
La ley argentina de inmigración de 1876 y su contexto histórico
}

\author{
Alejandro Fernández* \\ Universidad Nacional de Luján \\ Buenos Aires - Argentina
}

En el artículo se analizan las principales características de la ley de inmigración y colonización argentina de 1876 y las discusiones que se produjeron a raíz de su tratamiento en el Congreso Nacional. Se explican las relaciones entre esta ley y las políticas que la Argentina sostuvo durante la segunda mitad del siglo XIX en materia de inmigración, así como la gradual desvinculación de estas últimas respecto de las políticas de colonización. En la última parte se realiza un balance global de estas políticas, comparándolas con las de algunos países vecinos en la época.

\section{Palabras clave}

Inmigración - colonización - Política anti-crisis - Nicolás Avellaneda - Nicasio Oroño

* Alejandro Fernández tuve su formación como Profesor de Historia (Universidad de Buenos Aires), Magister en Ciencias Sociales (Facultad Latinoamericana de Ciencias Sociales) y Doctor en Historia (Universidad de Barcelona). Actualmente es Profesor Titular y Director de la Maestría en Ciencias Sociales en la Universidad Nacional de Luján. E-mail: fernan625@gmail.com. 


\section{The argentine immigration law of 1876 and its historical context}

\section{Alejandro Fernández}

The article analyzes the main characteristics of the Argentine immigration and colonization law of 1876 and the discussions that took place during its treatment in the National Congress. The relations between this law and Argentina's policies during the second half of the nineteenth century on immigration are explained, as well as the gradual untying of the latter with respect to colonization policies. In the last part, an overall assessment of these policies is made, comparing them with those of some neighboring countries at the time

\section{Key words}

Immigration - colonization - Anti-crisis policy - Nicolás Avellaneda Nicasio Oroño 


\section{Introducción}

La ley de Inmigración y Colonización, promulgada en 1876 por el presidente Avellaneda luego de un debate que se extendió por dos períodos parlamentarios, es a menudo mencionada como uno de los pilares legislativos de la modernización de la Argentina. A ello contribuye en primer lugar la tradicional asignación al inmigrante de una serie de atributos vinculados con dicha modernización, tanto en el plano de la economía como en el de la sociedad. En segundo lugar, la llamativa perduración secular de la ley, pese a los varios intentos de reformarla o derogarla a lo largo de las décadas y a las limitaciones que, en cuanto a las prácticas administrativas de recepción y admisión de los extranjeros, mellaron parte de su espíritu original. ${ }^{1}$ Por último, la apelación, tanto en los fundamentos del proyecto de ley como en los argumentos del debate a que dio lugar y en los antecedentes que en el mismo fueron mencionados, al nuevo horizonte de transformaciones que se abriría para la Argentina en el caso de que aquél fuese finalmente aprobado.

El presente artículo tiene como objetivo examinar las condiciones históricas de aprobación y aplicación de esta ley. La hipótesis que sostenemos es que el texto legislativo resumía los propósitos intervencionistas del Estado argentino en cuanto a la promoción de la inmigración mediante una serie de instrumentos concurrentes, algunos de los cuales ya estaban en vigencia. La sanción de la ley se produciría en un contexto caracterizado en parte importante por la crisis económica de 1873-76, a cuya superación aquélla debía contribuir, y en otra parte por la adopción de políticas de intervención en materia inmigratoria por parte de los Estados vecinos, especialmente Brasil. Ambos motivos propiciaron la aprobación del proyecto de ley de Avellaneda, que sin embargo debió soportar importantes cuestionamientos durante el trámite legislativo, en particular en el Senado. En los años siguientes, la puesta en práctica de la ley fue lenta y parcial, revelándose ineficaz en algunos

DEVOTO, Fernando. El revés de la trama: políticas migratorias y prácticas administrativas en la Argentina (1919-1949). En Desarrollo Económico, Buenos Aires, n. 162, p. 281-304, julio-setiembre de 2001. 
aspectos debido a los limitados recursos del Estado argentino y a la tenaz persistencia de los mecanismos espontáneos de inmigración. Sería durante la presidencia de Juárez Celman (1886-1890), por razones que trataremos de explicar, cuando dicho Estado logró por única vez una incidencia real sobre el flujo inmigratorio recurriendo a algunos de los instrumentos establecidos por la ley, como la intervención de los agentes radicados en Europa y el subsidio de pasajes, si bien ello no se relacionaba necesariamente con el proceso de colonización. Dicha incidencia concluyó con la crisis de 1890-92, límite final de nuestro trabajo.

Las políticas pro-inmigratorias de la Argentina durante el período que nos proponemos analizar, así como las ideologías que les dieron sustento, han concitado el interés de los investigadores, desde los inicios de la historiografía dedicada al tema y hasta la actualidad. ${ }^{2}$ Sin embargo, la mayoría de los estudios realizados no contemplan la perspectiva que emplearemos en esta ocasión, cual es la de correlacionar dichas políticas, y en particular la ley de inmigración de 1876, con las coyunturas económicas específicas que estaba atravesando el país, tanto en el momento del debate de aquélla como en los años sucesivos,

2 Véase por ejemplo HALPERIN DONGHI, Tulio. ¿Para qué la inmigración? Ideología y política inmigratoria en Argentina (1810-1914). En ----, El espejo de la historia. Problemas argentinos y perspectivas latinoamericanas. Buenos Aires: Sudamericana, 1987, p. 192-238; FRONTERA, Carlos. Las ideas sobre inmigración en el debate de la ley No 817 y en los periódicos de la época. En: Revista de Historia del Derecho, Buenos Aires, n. 16, 1988, p. 287-319; NOVICK, Susana. Política y población. Argentina 1870-1989. Buenos Aires: Centro Editor de América Latina, 1992, 2 vols.; DEVOTO, Fernando. Políticas migratorias argentinas y flujo de población europea (1876-1925). En ----, Estudios sobre la emigración italiana a la Argentina en la segunda mitad del siglo XIX. Napoli: Edizioni Scientifiche Italiane, 1992, p. 45-68; NOVICK, Susana. Políticas migratorias en la Argentina. En OTEIZA, Enrique; NOVICK, Susana; ARUJ, Roberto. Inmigración y discriminación. Políticas y discursos. Buenos Aires: Prometeo, 2000; DEVOTO, Fernando y OTERO, Hernán, Veinte años después: una lectura sobre el pluralismo cultural y la historia nacional en la historiografía argentina. En Estudios Migratorios Latinoamericanos, n. 50, 2003, p. 181-227; DEVOTO, Fernando. Historia de la inmigración en la Argentina. Buenos Aires: Sudamericana, 2003; NOVICK, Susana. Migración y políticas en Argentina: tres leyes para un país extenso (1876-2000). En Cuadernos del Pensamiento Crítico Latinoamericano. Buenos Aires: CLACSO, 2008; PÉREZ, Mariana (selección y estudio preliminar). Inmigración y colonización. Los debates parlamentarios del siglo XIX. Los Polvorines: Universidad Nacional de General Sarmiento, 2012. 
en que se trató de poner en práctica sus principales disposiciones. Por otro lado, no han concentrado su atención en los mecanismos de intervención estatal sobre el flujo poblacional que siguieron en vigencia incluso después de la crisis de 1890, como la actuación del Departamento General de Inmigración en la recepción, alojamiento, traslado y colocación laboral de los nuevos inmigrantes. Se trata por lo tanto de aportar aquí a esos aspectos menos trabajados hasta el momento, proponiendo una nueva interpretación sobre los objetivos de la ley y de la forma de aplicarla.

El artículo comprende cuatro partes. En la primera de ellas se analiza el proyecto presentado por el Poder Ejecutivo y los objetivos que se planteaba dentro de la coyuntura económica, política e internacional en la cual fue gestado. En la segunda se consideran los antecedentes de la ley, destacando las continuidades con políticas ya vigentes en materia inmigratoria. La tercera está orientado a desmenuzar el debate parlamentario del proyecto, las principales posiciones enfrentadas y las modificaciones que se introdujeron en ambas cámaras. Una atención especial se presta a las polémicas que aparecen en el debate, sobre todo la referida a la contraposición entre inmigración espontánea e inmigración dirigida o "artificial". En la cuarta, finalmente, se considera la repercusión de la aprobación de la ley en los principales periódicos de las colectividades extranjeras establecidas en el país y se realiza una evaluación de las tendencias del movimiento migratorio de los años siguientes, hasta la crisis de 1890-92, tratando de determinar si las mismas respondieron a las expectativas planteadas en 1875-76, tanto por lo que se refiere al total del flujo como a las procedencias nacionales. En esta parte también se analiza la gradual implementación por parte del Estado de algunas de las medidas previstas en la ley, pero luego acotadas, sea por limitaciones presupuestarias, sea porque la fuerte 
recuperación de la corriente inmigratoria durante la década de 1880 atenuó las urgencias de la anterior.

\section{Convocando a los inmigrantes}

En agosto de 1875 el presidente Avellaneda y su ministro del Interior Simón de Iriondo remitieron su proyecto a la Cámara de Diputados, sosteniendo que, si bien todos estaban convencidos de que la inmigración europea constituía el medio más adecuado para asegurar la prosperidad, hasta entonces poco se había avanzado, tanto en la legislación sobre el tema como en el intento de atraer las corrientes de población más adecuadas a las necesidades del país:

Hasta ahora no se ha buscado la inmigracion, aceptándose la que espontáneamente ha querido venir á la República, y en su internacion y acomodo se invierten sumas considerables sin exámen, sin calificacion, sin averiguar siquiera si el inmigrante ha de ser un poblador útil, que con su trabajo aumente la produccion del país, y contribuya al fomento de la riqueza pública, y al mismo tiempo sus costumbres y su educacion contribuyan á consolidar los elementos de civilizacion, de órden y de paz.

En el proyecto presentado se previene este mal, pues sin incluir la inmigración espontánea se procura elegirla buscándola en el norte de Europa y otros países del Sud, donde es tan fácil encontrarla en condiciones más adecuadas que aseguren para nosotros los resultados buscados. ${ }^{3}$

La apuesta por una política que a la vez promoviera y seleccionara la inmigración debía concretarse a través de cuatro acciones principales del Estado: el adelanto de pasajes marítimos a las familias que estuviesen dispuestas a instalarse como agricultores en las colonias, la donación gratuita de tierra o su venta a largos plazos, el traslado gratuito desde el puerto de desembarco hasta el lugar elegido para instalarse y el adelanto por un año de víveres, semillas, útiles y animales de labor y de cría. Si bien no se establecían límites o prohibiciones nacionales

3 COngreso nACIONAL. Diario de sesiones de la Cámara de Diputados. Año 1875. Buenos Aires: Imprenta Coni, 1876. t.II, p. 1190-1191. 
para la entrada de inmigrantes según sus orígenes, en el artículo 76 del proyecto se estipulaba que el Poder Ejecutivo fomentaría especialmente la llegada de los provenientes del norte de Europa, subvencionando para ello a determinadas líneas de vapores. La intervención del Estado, sin embargo, no se agotaba en la selección y traslado de agricultores a través del Departamento General de Inmigración, puesto que la mensura y el loteo consiguientes le corresponderían a otra agencia pública: la futura Oficina de Tierras y Colonias. Asimismo, la gestión sucesiva de cada emprendimiento quedaría en manos de un comisario administrador designado por el Poder Ejecutivo. La totalidad del gasto necesario para poner en marcha el proyecto se financiaría mediante la emisión de títulos de la deuda pública. ${ }^{4}$

Este intento de relanzamiento de la corriente inmigratoria se producía en el contexto de una fuerte crisis económica internacional, con importantes repercusiones en la Argentina. La caída del precio de las exportaciones, que alcanzó un promedio del 25 por ciento entre 1872 y 1878, afectó particularmente al sector que venía encabezando la vinculación del país con el mercado mundial, el lanero. El monto total de las ventas al exterior disminuyó en un veinte por ciento en el mismo lapso, mientras que la caída de las importaciones fue aún mayor, ya que descendieron a la mitad entre 1873 y $1876 .{ }^{5}$ Dada la fuerte concentración de los ingresos del Estado en la aduana, se debió encarar una política de austeridad presupuestaria. ${ }^{6}$

4 Ibidem, p.1191-1197. Una crítica que aparecía en los fundamentos del proyecto era que hasta entonces se había pretendido instalar a los inmigrantes sólo en los alejados y poco poblados territorios nacionales. Por ello en la nueva propuesta se admitía que también las provincias y los particulares pudieran colonizar tierras en acuerdo con la Nación. Si las provincias no cedían sus tierras sino que emprendían la colonización por sí mismas de acuerdo con las estipulaciones del proyecto, la Nación se comprometía a auxiliarlas financieramente.

5 FERRERES, Orlando. Dos siglos de economía argentina (1810-2004). Buenos Aires: Fundación Norte y Sur, 2004, p. 590-591.

6 MÍGUEZ, Eduardo. Historia económica de la Argentina. De la conquista a la crisis de 1930. Buenos Aires: Sudamericana, 2008, p. 166-167. 
La crisis también repercutió fuertemente sobre el empleo, provocando una reducción de la inmigración. Como se observa en el gráfico 1, los años en que se debatió y aprobó el proyecto de ley en el Congreso se caracterizaron por una fuerte caída del flujo inmigratorio: luego del récord alcanzado en 1873, con algo más de 75 mil ingresos, los registros de los tres años sucesivos fueron más magros. El de 1876, en particular, fue en ese sentido el peor de toda la década, si exceptuamos a 1871, un año excepcionalmente malo si tenemos en cuenta que en el mismo se produjo una grave epidemia de fiebre amarilla en la ciudad de Buenos Aires. Aunque no era su único objetivo, la ley estaba pensada como uno de los instrumentos anti - cíclicos de la política económica -junto con la inversión en ferrocarriles y la continuidad de la expansión de la frontera en la provincia de Buenos Aires-, en la medida en que la recuperación de la corriente inmigratoria contribuiría al incremento de la producción, del consumo, de las exportaciones y, en última instancia, de la recaudación aduanera. Un segundo propósito apuntaba a la diversificación de la inmigración por procedencias. En este sentido, el cuadro 1 nos muestra la muy elevada concentración que hasta ese momento presentaba el origen italiano, superior al cincuenta por ciento en todos los años desde 1857, en que comienza el relevamiento estadístico de la inmigración.

Más allá de la crisis, otras razones contribuyen a explicar el planteo del proyecto de inmigración y colonización en 1875. Por una parte, Avellaneda había demostrado en numerosas ocasiones su adhesión a los planes de impulso de la agricultura basados en la incorporación de campesinos europeos, a los que, en su opinión, se debía brindar la oportunidad de adquirir tierras a precios razonables. ${ }^{7}$ A ese propósito estaban encaminadas varias de las medidas que adoptó como ministro

7 Ver por ejemplo AVELLANEDA, Nicolás. Estudios sobre las leyes de tierras públicas [1865]. En -----, Escritosy discursos. Buenos Aires: Compañía Sudamericana de Billetes de Banco, 1910, vol. V, p. 11-257. También su prólogo a BARROS, Álvaro. Actualidad financiera de la República Argentina [1875]. En ----, Indios, frontera y seguridad interior. Buenos Aires: Solar-Hachette, 1975, p. 137139. En este texto Avellaneda sostenía que la conquista del territorio hasta ese momento en manos indígenas sólo podría consolidarse cuando esa población inmigrante lo hubiese poseído y fecundado. 
en la provincia de Buenos Aires, donde trató de extender los centros poblados con tal método, y algunas de las leyes nacionales contemporáneas de la de inmigración y colonización, como la que amplió las concesiones de tierras a la colectividad galesa instalada en Chubut o la que ordenó la mensura y venta de lotes en la colonia Caroya, de la provincia de Córdoba. ${ }^{8}$

Es probable que también contribuyera al planteo la alianza política que llevó a Avellaneda a la presidencia. Como es sabido, en dicha alianza le cupo un papel central al autonomismo porteño, que incluía en su propia agenda electoral un amplio programa de colonización con familias inmigrantes, en el que el Estado nacional dispondría de mayores recursos y poderes que los que había contado hasta ese momento. Estas ideas fueron defendidas en la legislatura bonaerense por destacados integrantes del partido dirigido por Adolfo Alsina, como Miguel Navarro Viola o Aristóbulo del Valle. ${ }^{9}$ De hecho, la prensa vinculada al autonomismo fue la que apoyó más firmemente el proyecto Avellaneda-Iriondo una vez que fue presentado al Congreso. Así, La Tribuna argüía que la Argentina había descuidado hasta entonces el recurso a la inmigración extranjera, a la que consideraba clave no sólo por los brazos que aportaba sino por las enseñanzas de economía, orden y moralidad que introduciría. Según este diario, existían dos métodos para promoverla:

El uno es el método lento de la inmigracion espontánea, que nos ha hecho malgastar diez años en experimentos estériles. El otro es el sistema artificial de población, que fomenta en grande escala las espediciones de inmigrantes, y dá al gobierno una intervención directa y positiva. ${ }^{10}$

8 El debate sobre la mensura y el loteo de la futura colonia Caroya, en terrenos del Colegio Nacional de Monserrat, puede verse en CONGRESO NACIONAL. Diario de sesiones de la Cámara de Diputados. Año 1876. Buenos Aires: Imprenta y Librería de Mayo, 1877, t. I, p. 142-170.

9 CONVENCIÓN CONSTITUYENTE DE LA PROVINGIA DE BUENOS AIRES. Debates de la..., 1870-1873, vol. II, p. 502 y ss.; CÁMARA DE DIPUTADOS DE LA PROVINCIA DE BUENOS AIRES. Diario de sesiones, 1876, p. 350.

${ }^{10}$ Opiniones de la prensa nacional sobre el proyecto de ley de inmigración. Documentos oficiales de la actual administración sobre la materia. Buenos Aires: Imprenta de "La Tribuna", 1875, p. 
Desde luego, La Tribuna se congratulaba de que el gobierno hubiese optado por este segundo. Si bien aprobaba el hecho de que no hubiese restricciones de los inmigrantes por orígenes, preveía que habría una selección a través del adelanto de pasajes, que estaría limitado a las corrientes que venían con el propósito de radicarse en el campo para trabajarlo. ${ }^{11}$ La República, por su parte, sostenía que la ley habría de ser la más importante de la presidencia de Avellaneda y auguraba que con ella se acababa el tiempo de la inmigración que llegaba al país atraída por una prensa halagadora y por unos agentes inescrupulosos y que, a falta de otra alternativa, terminaba radicándose en las ciudades, empleándose en la construcción de casas o de líneas de tranvía. Ahora el país estaba haciendo suyos los principios de la colonización emprendida en algunas provincias, como Entre Ríos, que habían logrado arraigar al inmigrante otorgándole la tierra. ${ }^{12}$

Otro factor muy importante que propició la presentación del proyecto legislativo se encuentra en el hecho de que algunos de los países vecinos habían comenzado a adoptar sus propias políticas de atracción de la inmigración europea mediante la concesión de beneficios para el traslado, alojamiento y radicación, con una intervención directa del Estado. Uruguay, por ejemplo, creó a fines de 1865 una Comisión Central de Inmigración en la órbita del Ministerio de Hacienda, cuyas atribuciones incluían la designación de agentes en el exterior, la supervisión de las condiciones del desembarco de los inmigrantes, el alojamiento y manutención en Montevideo por unos días, el monitoreo de su instalación en la campaña, la intervención en los contratos de trabajo entre ellos y los particulares que los emplearan y el auxilio legal

8-9.

${ }^{11}$ Sobre La Tribuna y sus vínculos con el autonomismo, DE MARCO, Miguel Ángel. Historia del periodismo argentino. Desde los orígenes hasta el Centenario de Mayo, Buenos Aires: Editorial de la Universidad Católica Argentina, 2006, p. 210-21 1; HALPERÍN DONGHI, Tulio, José Hernández y sus mundos. Buenos Aires: Sudamericana-Instituto Torcuato Di Tella, 1985, p. 145-146.

${ }^{12}$ Un proyecto sobre inmigración y colonización y un aplauso. En Opiniones de la prensa nacional..., op.cit., p. 27-33. 
en caso de que se vieran involucrados en causas judiciales durante el año siguiente a su arribo. ${ }^{13}$

A mediados de la década de 1870 Uruguay recibía unos quince mil inmigrantes anuales, de los cuales aproximadamente un diez por ciento obtenía su primer empleo a través de la Comisión. En el informe correspondiente a 1875 se reconocía que esa inmigración era de carácter espontáneo y no planificado, pero se sugería la conveniencia de conectar el movimiento migratorio con la colonización mediante impuestos, a fin de atraer y financiar a los grupos considerados como más aptos para ese trabajo, como suizos o vascos. ${ }^{14}$ Sin embargo, Uruguay no contó con una ley general de inmigración hasta 1890, fecha en que fue aprobada siguiendo el modelo de la argentina. Por otro lado, en ese país no se daba un predominio de la inmigración italiana como contemporáneamente presentaba la Argentina, sino que la distribución entre aquélla y la española era mucho más pareja.

Brasil, por su parte, encaró en esa misma década una política más activa en el exterior, encargando a los cónsules y legados en Europa que divulgasen la intención del gobierno imperial de conceder a los individuos emigrantes una serie de ventajas para el traslado e instalación en el país. ${ }^{15} \mathrm{Al}$ mismo tiempo, crecía el número de contratos del gobierno con las empresas colonizadoras e introductoras de inmigrantes del centro y norte de Europa, como alemanes, suizos y polacos. Esta política estaba principalmente orientada a su radicación como pequeños propietarios en la agricultura y todavía guardaba escasa relación con la producción de café. Pero además de los objetivos económicos, perseguía uno racial, en la medida en que el fomento y protección de la inmigración estaban pensados para grupos étnicos a los que se

${ }^{13}$ REPÚBLICA ORIENTAL DEL URUGUAY. Estatuto y reglamento interno de la Comisión Central de Inmigración. Montevideo: Imprenta del Telégrafo, 1866, passim.

${ }^{14}$ REPÚBLICA ORIENTAL DEL URUGUAY. COMISIÓN GENTRAL DE INMIGRACIÓN. Informe anual de 1875. Montevideo: Imprenta a Vapor de "La Tribuna", 1876, p. 5-6.

${ }^{15}$ Circular del 25 de abril de 1865, citada en GONÇALVES, Paulo Cesar. Mercadores de braços. Riqueza e acumulação na organização da emigração europeia para o Novo Mundo. São Paulo: Alameda, 2012, p. 146. 
percibía como la antítesis de la brasilidade. ${ }^{16}$ De todas maneras, más que las medidas ya adoptadas, lo que influía sobre la política inmigratoria argentina, como veremos, era la posibilidad de que Brasil finalmente recurriera a una opción más agresiva de atracción de colonos europeos en caso de abolir la esclavitud, lo cual podía ser anticipado con bastante certeza, al menos desde la sanción de la libertad de vientres en 1871 .

Las connotaciones raciales tampoco estuvieron ausentes en las acciones encaradas en la misma época por el Estado chileno, si bien las necesidades económicas y demográficas fueron las determinantes. La colonización del sur del país debió enfrentar las dificultades de una inmigración espontánea mucho menos nutrida que la que recibía la Argentina o incluso el Uruguay, por lo que el interés gubernamental por promoverla se manifestó reiteradamente durante las décadas centrales del siglo XIX. La ley de 1845 que facultaba al Poder Ejecutivo a constituir colonias de extranjeros, los diversos decretos de la década de 1850 por los que se autorizaron los emprendimientos específicos, principalmente poblados con inmigrantes alemanes y, por último, la creación en 1871 del Ministerio del Exterior y de la Colonización, fueron los principales hitos de esa política. Sin embargo, no fue hasta 1882 que se instaló una agencia de colonización e inmigración en Europa, momento que coincide con la definitiva incorporación política y administrativa de la Araucanía. ${ }^{17}$

\section{Primeras tentativas de intervención}

Pese a las críticas que formulaba a la política inmigratoria anterior, buena parte de las disposiciones contenidas en el proyecto Avellaneda-Iriondo contaban asimismo con varios antecedentes en la legislación argentina. En 1854 la legislatura de Buenos Aires había autorizado al

16 SEYFERTH, Giralda. Colonização, imigração e a questão racial no Brasil. En Revista USP. São Paulo, n. 53, p. 117-149, março - maio 2002.

17 STABILI, Maria Rosaria, Las políticas inmigratorias de los gobiernos chilenos desde la segunda mitad del siglo pasado hasta la década de 1920. En Estudios Migratorios Latinoamericanos, Buenos Aires, n. 2, p. 181-202, abril 1986. 
gobierno a constituir una comisión de individuos de distintas nacionalidades con el objetivo de otorgar protección a los inmigrantes que arribaran. La entidad, llamada Asociación Filantrópica de Inmigración, recibía fondos de la provincia y, entre otras funciones, administraba un asilo cercano al puerto en el que se ofrecía alojamiento y manutención gratuitos durante ocho días a los recién llegados que así lo requirieran. El organismo también debía asesorar al gobierno en la materia de su competencia, compilar las listas de los inmigrantes desembarcados y publicar folletos en Europa que publicitaran a la Argentina como país de inmigración. ${ }^{18}$ La presencia entre los miembros de la Asociación de algunos de los más destacados propietarios y empresarios rurales de la época -como Olivera, Gowland, Pereyra, Martínez de Hoz, Armstrong o Casares- puede explicarse, además de los motivos filantrópicos, por el interés en introducir en el país una mano de obra más entrenada en la práctica de las nuevas formas productivas. ${ }^{19}$

En agosto de 1869, por decreto del presidente Sarmiento, fue creada la Comisión Central de Inmigración, que absorbía a la anterior y heredaba sus funciones, añadiendo otras nuevas, como la inspección sanitaria de los buques de pasajeros o la defensa de los derechos de los colonos en sus relaciones con los contratistas de colonización. Sin embargo, mantenía un carácter mixto, puesto que incorporaba como integrantes a algunos de los empresarios, terratenientes y capitalistas que hasta ese momento contribuían a la conservación del asilo, con el propósito de que tanto ellos como otros particulares y corporaciones siguieran aportando a las suscripciones para el alojamiento de los inmigrantes. Todos los agentes de inmigración designados hasta ese mo-

${ }^{18}$ ALSINA, Juan. La inmigración europea en la República Argentina. Buenos Aires: Imprenta, 1898, p. 34-41.

${ }^{19}$ DJENDEREDJIAN, Julio; BEARZOTTI, Sílcora; MARTIRÉN, Juan Luis. Expansión agrícola y colonización en la segunda mitad del siglo XIX, T. 6 de la Historia del capitalismo agrario pampeano. Buenos Aires: Teseo-Universidad de Belgrano, 2010, vol. I, p. 152-153. 
mento, tanto en el interior del país como en el extranjero, quedaban integrados en la órbita de la nueva repartición. ${ }^{20}$

Considerando que "el mayor aliciente para la inmigración es la posesión de la tierra", la Comisión debía tratar de obtener concesiones del gobierno nacional o de los provinciales, a fin de llevar a cabo los proyectos de colonización. Por otro lado, debía ocuparse de crear una Agencia de Conchabos y de construir un mejor asilo que el existente, dado que este último ya resultaba insuficiente ante el creciente arribo de extranjeros. Pero también se le asignaba la tarea de activar en lo posible el contacto escrito entre los inmigrantes y "sus deudos y amigos en Europa", estableciendo una Agencia de Correspondencia en el asilo, por ser ésta "la más elocuente y atendida propaganda que pudiera hacerse", lo cual implicaba un reconocimiento de la importancia de los mecanismos micro-sociales y espontáneos que permitían continuar el movimiento emigratorio. ${ }^{21}$

Algunos de los objetivos enunciados quedaban en la práctica fuera del alcance real de la Comisión, dados los gastos y la cantidad de personal que habrían requerido. Sin embargo, en otros aspectos el trabajo de la misma arrojó resultados palpables. Así ocurrió por ejemplo con el alojamiento de los inmigrantes, ya que, además del asilo central de Buenos Aires, la Comisión logró instalar un segundo en Rosario. En 1870, cuando el total de inmigrantes recibidos por la Argentina fue de 40 mil, el primero albergó a 6.300, y el segundo a 660. Por otro lado, del total asilado en Capital, algo más de la mitad permaneció luego trabajando en la propia ciudad, y a otros se les otorgó pasaje gratis en los ferrocarriles del Oeste y del Sud. ${ }^{22}$ En cualquier caso, la Comisión se quejaba en ese año de que sólo tenía control sobre las características de los 6 o 7 mil que había albergado, mientras que nada sabía sobre

${ }^{20}$ COMISIÓN GENTRAL DE INMIGRAGIÓN. Fundación de la.... Sus propósitos y reglamento. Buenos Aires: Imprenta de Pablo Emilio Coni, 1869, p. 1-2.

${ }^{21}$ Ibidem, p. 7.

${ }^{22}$ COMISIÓN CENTRAL DE INMIGRACIÓN. Informe de la... 1870. Buenos Aires: Tipografía Italiana, 1871, p. 4-7. 
los otros 35 mil, aunque tenía información de que estaban llegando mendigos e inválidos. Estos datos arrojarían dudas acerca de la eficacia del sistema de los agentes del organismo radicados en el exterior. La propia Comisión era crítica respecto de la distribución de dichos funcionarios, ya que en varios casos estaban situados en países que contaban con una emigración espontánea hacia la Argentina, mientras que escaseaban en otros, como los del norte de Europa, cuya corriente habría sido deseable fomentar. Por otro lado, a la hora de evaluar las acciones de cada agente, la Comisión mostraba que algunos de ellos se ponían directamente en contacto con las poblaciones en las que era posible el reclutamiento de emigrantes -citando entre otros el ejemplo de Carlos Beck Bernard, agente en Suiza y Alemania-, pero que otros se limitaban a publicar folletos o anuncios en los periódicos del país correspondiente, cuyo impacto real era dudoso. ${ }^{23}$

A pedido de la Comisión, en 1871 se creó el cargo de Inspector de Colonias, a fin de contar con información más fidedigna de lo que ocurría con los inmigrantes empleados en tales emprendimientos del Litoral. Guillermo Wilcken, que previamente había sido uno de los integrantes de la Comisión Central de Inmigración del Uruguay y secretario de su homónima de la Argentina, fue designado Inspector. Al año siguiente, Wilcken elevó su conocido informe, en el que destacaba la prosperidad alcanzada por las 34 colonias de Santa Fe y Entre Ríos, en las cuales ya vivían más de tres mil familias. Según el informe, la mayoría de estas familias habían llegado al país a partir de 1856, en un estado de solemne pobreza, con pasajes y primeros gastos costeados por los gobiernos provinciales. Luego de un quinquenio inicial muy duro, lograron afianzarse y prosperar, y si en algún caso no lo hicieron, no habría sido por fallas del sistema de colonización, sino por la desidia de algunos de sus integrantes. Wilcken elogiaba el notable desarrollo de la agricultura cerealista logrado por las colonias y proponía una serie de mejoras que debían encarar los gobiernos en cuanto a transportes, educación y asistencia religiosa de los no católicos.

${ }^{23}$ Ibidem, p. 61-68. 
Más allá de los problemas puntuales, el cuadro general era optimista en cuanto a las posibilidades futuras de un sistema que combinaba la iniciativa del Estado, de las compañías colonizadoras y de los propios colonos interesados en el progreso. ${ }^{24}$

El informe Wilcken venía así a ratificar una línea de pensamiento que ganaba apoyos en la todavía reducida burocracia del Estado argentino que se ocupaba de la inmigración. Esa línea sostenía la necesidad de que los inmigrantes fueran seleccionados, reclutando en lo posible familias completas y laboriosas, directamente en los distritos agrícolas europeos, para luego otorgarles diversas facilidades que permitieran su traslado e instalación. Ello no sólo contribuiría a la prosperidad económica, sino que facilitaría la integración en el país receptor:

[Las estadísticas actuales] confirman á la Comision y demuestran hasta la evidencia, la importancia que tiene para el porvenir y progreso de estos países el atraer buena clase de inmigración; es decir: no aquella que forma el sobrante en las ciudades populosas, sino la que puede conseguirse en los distritos agrícolas; inmigrantes que se transporten en grupos de familias, con sus hábitos de trabajo, sobriedad y economía, dispuestos a arraigar en aquel pedazo de tierra que el pais les ofrezca, lo cual les prometa y luego les dé lo necesario para el presente y fundadas esperanzas de futura prosperidad. ${ }^{25}$

\section{El trámite parlamentario y el contenido final de la ley}

La Comisión de Legislación de la Cámara de Diputados examinó el proyecto de Avellaneda e Iriondo junto con otro, que había sido presentado por Onésimo Leguizamón como diputado en $1874 .{ }^{26}$ Este segundo tenía varias diferencias con el anterior. Una muy importante es que definía qué se entendería por inmigrante, es decir

\footnotetext{
${ }^{24}$ WILCKEN, Guillermo. Las colonias. Informe sobre el estado actual de las colonias agrícolas de la República Argentina. Buenos Aires: Imprenta, Litografía y Fundición de Tipos a Vapor de la Sociedad Anónima, 1873, passim.

${ }^{25}$ COMISIÓN GENTRAL DE INMIGRAGIÓN. Informe de la... 1870, op.cit., p. 19.

${ }^{26}$ En el momento en que la Cámara comenzó a considerar ambos proyectos, Leguizamón había pasado a ser Ministro de Justicia e Instrucción Pública del propio Avellaneda.
} 
el extranjero que poseyendo un determinado oficio (jornalero, artesano, industrial o profesor) llegara a la Argentina desde puertos europeos habiendo pagado pasaje de segunda o tercera clase. Curiosamente, la ocupación de agricultor o labrador no estaba incluida, lo cual parece guardar relación con que las ventajas que se otorgaban a los inmigrantes se referían al alojamiento y manutención, la bolsa de trabajo, el traslado al interior y el envío gratuito del correo, pero no a la concesión de tierras. A esos derechos se añadía la devolución de la diferencia entre el pasaje a la Argentina y a Estados Unidos en el caso de quienes procedieran de Bélgica, Suecia, Alemania, Inglaterra, Holanda y Noruega. Asimismo, el proyecto Leguizamón era bastante más explícito que el de Avellaneda-Iriondo respecto de las condiciones de seguridad e higiene de los buques que transportarían a los inmigrantes, de las funciones del Departamento de Inmigración a crearse y de los agentes en el exterior. En suma, se trataba de una propuesta que se ocupaba con mayor detalle de lo vinculado con la inmigración, pero que no incursionaba en la colonización. ${ }^{27}$

La Comisión de Legislación, presidida por el diputado Achával Rodríguez, llegó a una suerte de arbitraje entre ambos proyectos. Incorporó la segunda parte del enviado por el Ejecutivo, referida a colonización, haciendo suya la idea de que el acceso a la propiedad de la tierra era el medio más eficaz para atraer la inmigración. La única modificación relevante que introdujo en este aspecto fue que la Nación conservaría una parcela de tierra intercalada en cada sección de los territorios a colonizar, a fin de obtener un beneficio de su futura valorización. En cuanto a la primera parte, la Comisión mantuvo la línea de intervención estatal, adoptando del proyecto Leguizamón, y en parte ampliando, las atribuciones del Departamento de Inmigración y de los agentes en el exterior. Pero al mismo tiempo extendió a los agricultores las ventajas de quienes ejercían las restantes profesiones -entre ellas la del pago de la diferencia del pasaje con Estados Unidos, sea cual

${ }^{27}$ CONGRESO NAGIONAL, Diario de sesiones de la Cámara de Diputados. Año 1875. Buenos Aires: Imprenta Coni, 1876, t. II, p. 1197-1204. 
fuere su origen nacional- y agregó, en la definición de inmigrante, a quienes llegaban con pasaje pagado por la Nación, las provincias o las empresas particulares, todo lo cual era consistente con la adopción de la parte referida a colonización, que estaba ausente en el proyecto del diputado entrerriano. ${ }^{28}$

Más allá de sus propósitos, los debates en el recinto de la Cámara revelaron que algunas de las proyectadas intervenciones del Estado resultaban difíciles de llevar a la práctica. Así, un capítulo del proyecto que suscitó larga controversia fue el referido a la creación de las estafetas postales a través de las cuales los inmigrantes enviarían sus cartas, de manera gratuita y durante los dos primeros años de residencia en el país, a los familiares y paisanos que permanecían en Europa. Si bien la mayoría de los diputados coincidía en que ninguna noticia era más creíble que la transmitida en esa correspondencia, durante la discusión se fueron revelando las serias dificultades de implementación del sistema si se trataba de extenderlo a todas las colonias y a todos los agentes en el exterior, por lo que fue suprimido. ${ }^{29}$

Pero la línea de intervención estatal no fue globalmente impugnada en Diputados, como se advierte en las discusiones sobre la segunda parte del proyecto, en las cuales las sugerencias de reforma no reducían los propósitos de planificación de la colonización, sino que más bien tendían a extenderlos. ${ }^{30}$ Así aconteció por ejemplo con el intercambio de opiniones acerca de la forma de dividir los lotes en torno de los pueblos que se crearían en cada sección a colonizar, de la asignación agrícola o ganadera que se les daría a los mismos o incluso de la longitud de cada

${ }^{28}$ Ver el proyecto de la Comisión de Legislación en Ibídem, p. 1179-1191.

${ }^{29}$ El capítulo sobre las estafetas postales propuesto por la Comisión en Ibidem, p. 1181-1 182; el debate que llevó a su rechazo en p. 1205-1208. Pese a este rechazo, en el Senado hubo una moción del tucumano Uladislao Frías para reponer este sistema, con cargo al Departamento de Inmigración, sin alcanzar los votos necesarios. Cf. CÁMARA DE SENADORES. Sesiones de 1876. Buenos Aires: Compañía Sud-Americana de Billetes de Banco, reimpresión, 1900, p. 578.

${ }^{30}$ Esto coincidiría con ese ambiente de amplio consenso acerca del rol planificador del Estado en materia de colonización que ha sido señalado en DJENDEREDJIAN, Julio; BEARZOTTI, Sílcora; MARTIRÉN, Juan Luis. Expansión agrícola y colonización..., op.cit., p. 144-145. 
lado de las futuras manzanas, cuestiones que se trató de establecer fehacientemente en la propia ley y no en su futura reglamentación. La Cámara venía a refrendar así la minucia reglamentaria y uniformadora ya observable en el proyecto Avellaneda-Iriondo, pese a que el mismo debía aplicarse en colonias que necesariamente serían muy diferentes y que se erigirían a cientos de kilómetros de distancia entre sí. ${ }^{31}$

Una vez aprobado, el proyecto fue girado al Senado. Esta cámara decidió no tratarlo en el mismo período legislativo, dado lo avanzado del año y la discrepancia de opiniones que se advertía entre algunos de sus miembros, lo que auguraba un trámite más complicado que en Diputados. A cambio, sí estuvo dispuesta a aprobar, en decisión que en octubre ratificaría la cámara baja, una ley que autorizaba provisoriamente al Poder Ejecutivo a fomentar la inmigración y la colonización, en los territorios nacionales y en los cedidos por las provincias, mediante la concesión de lotes que no excedieran de las cien hectáreas por familia y el adelanto de gastos para instalación. Se trataba de un acuerdo que concedía un amplio margen de acción al gobierno nacional, aunque por fuera del sistema planificado de las colonias, mientras se trataba en el Senado el proyecto Avellaneda-Iriondo reformado en Diputados. No obstante, una significativa ausencia en esta ley era la de la forma de financiar las acciones requeridas, ya que, si bien se fijaba una suma máxima para tal propósito, no se autorizaba la toma de crédito, lo cual parecía limitar la obtención de los recursos al rubro de rentas generales, que, como vimos, se encontraba con importantes limitaciones debido a la crisis económica. ${ }^{32}$

${ }^{31}$ Inclusive los despachos en minoría, que fueron presentados por integrantes de la Comisión de Legislación para algunos artículos, mantenían esa impronta, refiriéndose por ejemplo a la cantidad de lotes a repartir por cada familia que se instalara en las colonias durante sus dos primeros años, $o$ al método más idóneo para realizar la mensura de las superficies. Cf. CONGRESO NACIONAL, Diario de sesiones de la Cámara de Diputados. Año 1875, op.cit., T. II, p. 1230-1235.

${ }^{32}$ El texto de la ley provisoria, aprobada sin observaciones en Diputados tras ser girada por el Senado, en Ibídem, p. 1464-1465. Conviene aclarar también que el escueto texto sólo nombraba a la inmigración una vez, al definir el objetivo general de fomentarla, pero no entraba a considerar los medios para trasladarla, recibirla y alojarla. 
Precisamente, la cuestión de la financiación del fomento de la inmigración fue una de las razones por las que Nicasio Oroño se opuso tenazmente al proyecto Avellaneda-Iriondo una vez que éste entró en revisión en el Senado. La emisión de nuevos títulos de la deuda le resultaba un instrumento muy peligroso, en la medida en que depreciaría el valor de los ya circulantes, precisamente en un momento de crisis, cuando se temía la suspensión del pago de amortizaciones de la deuda y de las garantías de las concesiones ferroviarias. Su segunda objeción se refería a la potestad del Estado nacional para establecer colonias en territorios nacionales cuando todavía no se habían fijado con precisión los límites de algunas provincias, tema sobre el cual el propio Oroño había presentado en 1869 un proyecto al Senado. La tercera discordancia, más de fondo, se refería a que, a su criterio, existía un impedimento constitucional para que el Congreso nacional legislara sobre colonización en las provincias, una de las variantes contempladas en el proyecto del Ejecutivo. En el mismo sentido, sostuvo que las provincias podrían perder independencia frente a la Nación si, atraídas por los beneficios que se les ofrecían, entregaban tierras para colonizar. ${ }^{33}$

Por todas estas razones, Oroño consideraba que el proyecto girado por Diputados no podía ser aprobado y debía girárselo a comisión, criterio en el que fue apoyado por el senador cordobés Cortés y por el correntino Torrent. En su respuesta a estas observaciones, el ministro Iriondo, adversario político de Oroño en Santa Fe, reconoció que habría sido mejor aprobar la ley una vez que estuviesen claramente delimitadas las provincias y los territorios nacionales, aunque, a falta de ese paso, era perentorio avanzar en la cuestión de la inmigración y la colonización. Las intervenciones de otros senadores en respaldo de Iriondo, como la del catamarqueño Molina, abundaron en que resultaba urgente contar con una base legislativa en materia de inmigración, pese a que había puntos de la ley que quizá no pudieran implementarse de inmediato. A continuación, el proyecto fue aprobado en

${ }^{33}$ CÁMARA DE SENADORES. Sesiones de 1876, op.cit., p. 519-521. 
general, con sólo los votos negativos de Oroño y Torrent, y luego se inició la discusión sobre los artículos.

Oroño volvió entonces a impugnar algunos de las disposiciones contenidas en la ley, como por ejemplo la del pago a los futuros inmigrantes de la diferencia del importe del pasaje entre Estados Unidos y la Argentina desde su puerto de origen, lo cual implicaba una obligación muy superior a los medios con los que contaba el erario, o la referida a la injerencia de los agentes radicados en Europa en los contratos de transporte entre aquéllos y las compañías de navegación. ${ }^{34}$ Estas discrepancias puntuales del senador santafesino se integraban en una más sustancial, derivada de su confianza en las bondades de la inmigración espontánea frente a la apuesta por la "artificial" del proyecto del Ejecutivo. En su visión, mientras que la primera resultaba estimulada por el ejemplo de las ventajas que ofrecía el país, sin necesidad de planes específicos de colonización, la segunda obligaba a realizar ingentes gastos, que se debían reiterar cada año, so pena de perder todo lo invertido con anterioridad. Comentando el panorama que presentaban las más de cuarenta colonias santafesinas, concluía que las que más prosperaban eran las que no habían obtenido ni tierra ni ayuda del gobierno, mientras que las tres que habían recibido ambas cosas (Esperanza, San Urbano y San José de la Esquina) no se destacaban por su productividad. ${ }^{35}$ En el mismo sentido, al plantear una comparación con Estados Unidos que reaparecería varias veces en el debate, sostuvo que los emigrantes del norte de Europa no se orientaban hacia ese destino debido al costo del pasaje o a las ventajas que les ofrecía el Estado sino a que allí encontraban su segunda patria, sus leyes, sus costumbres, su idioma. En apoyo de la postura de Oroño, el senador Torrent presentó un cuadro similar respecto de la colonización de las provincias de Corrientes y Entre Ríos, explicando que los

\footnotetext{
${ }^{34}$ Sobre los agentes y su intervención, cf. Ibidem, p. 563; sobre el pago de la diferencia del pasaje, p. 579.

35 Ibidem, p. 580-581.
} 
Estados respectivos habían hecho inmensas erogaciones en ese rubro, sin alcanzar unos resultados que las justificaran. ${ }^{36}$

Como es sabido, el interés de Oroño por la colonización basada en inmigrantes no era nuevo. Él mismo había participado de ese proceso como propietario rural y, en la esfera política, lo había defendido al menos desde los comienzos de su actuación como diputado nacional, en 1862. Luego había sostenido las mismas ideas como gobernador de Santa Fe, entre 1865 y 1868, un período de fuerte expansión de las colonias. En 1868, cuando fue electo senador nacional, presentó su propio proyecto de colonización con inmigrantes en territorios nacionales del norte y el sur del país. Por supuestas facilidades de adaptación climática, en los primeros proponía la instalación de italianos, españoles y franceses del mediodía, mientras que para los segundos debía promoverse la incorporación de alemanes, ingleses, escoceses y escandinavos. ${ }^{37}$ La defensa de la colonización privada frente a la estatal también había sido planteada por él con anterioridad al debate sobre la ley, apoyando la venta de tierras públicas si con ello se lograba la integración de los inmigrantes europeos en el campo. ${ }^{38}$

Finalmente, el proyecto fue aprobado en octubre de 1876 con sólo una reforma fundamental, la supresión del artículo 17 que disponía la devolución del importe del pasaje entre los destinos de Argentina y Estados Unidos desde el puerto de procedencia, más algunas menores, luego votadas en Diputados. Se confirmaban por lo tanto las obligaciones del Estado argentino respecto del alojamiento, manutención y traslado al interior de los inmigrantes, las de las compañías navieras en cuanto a las condiciones de seguridad e higiene de los barcos, las fun-

${ }^{36}$ Ibidem, p. 574-575. Puede encontrarse un antecedente de la postura de Oroño respecto de las ventajas de la inmigración espontánea en la defensa de ésta realizada por Mitre en el propio ámbito del Senado, en 1870. Cf. DJENDEREDJIAN, Julio. Gringos en las pampas. Inmigrantes y colonos en el campo argentino. Buenos Aires: Sudamericana, 2008, p. 96-98.

${ }^{37}$ DE MARCO, Miguel Ángel. Introducción. En OROÑO, Nicasio. Obras completas. Santa Fe: Universidad Nacional del Litoral-Academia Nacional de la Historia, 2004, vol. I, p. 13-33.

${ }^{38}$ Cf. OROÑO, Nicasio, La verdadera organización del país o realización legal de la máxima "gobernar es poblar". Buenos Aires: Imprenta, Litografia y Fundición de Tipos a Vapor, 187 1, passim. 
ciones del Departamento General de Inmigración y las de los agentes radicados en Europa. El derecho a los pasajes transatlánticos o a los anticipos sobre su costo quedaba acotado a los agricultores contratados para las colonias de la República -es decir que no se lo suprimía por completo-, al igual que acontecía con los víveres, herramientas y animales durante los primeros tiempos de instalación. Como se ha señalado, la Oficina de Tierras y Colonias tendría a su cargo la subdivisión y mensura de las tierras aptas para colonizar y a continuación el Departamento de Inmigración enviaría las familias seleccionadas. En resumidas cuentas, sin excluir la inmigración espontánea, la nueva ley dejaba un margen considerable a la intervención directa del Estado. Al menos en el papel, los agentes del gobierno buscarían y seleccionarían a los candidatos en sus países de origen, luego éstos serían trasladados por compañías de navegación supervisadas y en parte subsidiadas, a su arribo los inmigrantes serían alojados, mantenidos y trasladados hasta los lugares en donde estarían preparadas las tierras para que las comenzaran a trabajar y, según cumpliesen las condiciones estipuladas, para que las recibiesen en donación o las adquiriesen a un precio módico. ${ }^{39}$

\section{Repercusiones de la ley y sus efectos sobre las migraciones subsiguientes}

Una de las principales cajas de resonancia de la ley de inmigración y colonización fue la prensa de las colectividades extranjeras radicadas en el país. Veamos a continuación como reflejaron su aprobación y las iniciativas subsecuentes los tres periódicos que formaban parte de ese grupo y más se ocuparon de la cuestión. En primer lugar, L’Operaio Italiano, que había comenzado a circular en 1872. Luego de una fase pro-republicana, este diario se convirtió en monárquico, contando con financiación de la legación italiana. Esto explicaría que pudiera sobrevivir hasta 1895, un período bastante más prolongado que la media de

${ }^{39}$ El textodefinitivo, tal comofue aprobadopor el Congreso, puedeverse en Ley de inmigración y colonización de la República Argentina. Buenos Aires: Imprenta, Litografía y Fundición de Tipos de Vapor, 1876. 
los rotativos de ese origen. ${ }^{40}$ En L'Operaio eran frecuentes las críticas en contra de las arbitrariedades que sufrían los colonos de origen italiano por parte de los funcionarios políticos o judiciales, de la desidia con que se permitían los ataques indígenas contra ellos en ciertas regiones y de las dificultades económicas que se les presentaban en sus tareas agrícolas. ${ }^{41}$ En línea con esa posición, L’Operaio apoyó la ley de inmigración en aquellos aspectos en los que el Estado argentino tendía a sostener los emprendimientos colonizadores, pero se opuso categóricamente a la acción de los agentes designados en Europa, a los que calificaba como traficantes de carne humana o de manera similar. Por el contrario, destacaba constantemente que un país como la Argentina, a diferencia de Venezuela, Perú o Brasil, no necesitaba gastar fortunas en avisos o en funcionarios pagos y que debía abandonar todo intento de "inmigración artificial". Es por lo que, luego de aprobada la ley, uno de sus blancos predilectos sería el Comisario General de Inmigración, Juan Dillon, debido a sus propósitos de encauzar de manera planificada los contingentes de extranjeros que llegaban al país. ${ }^{42}$

A diferencia de L'Operaio, El Correo Español, fundado en 1872, se orientaba más claramente a la información y opiniones sobre los sectores urbanos de la economía, principalmente el comercio, lo cual estaba en consonancia con la estructura ocupacional de ambas colectividades. Otra importante diferencia radicaba en que para 1876 el rotativo español mantenía una postura decididamente anti-gubernamental, con frecuentes intervenciones desde sus páginas en la política nacional, en general coincidentes con las de la facción encabezada por el general

${ }^{40}$ Cf. BERTAGNA, Federica. La stampa italiana in Argentina. Roma: Donzelli, 2009, p. 25.

${ }^{41}$ Ver por ejemplo Colonie agricole. En L'Operaio Italiano, 17 de julio de 1877, sobre las penurias sufridas por familias de agricultores en Carmelo (Uruguay) y en las inmediaciones de Río IV (Córdoba), y Riscatto dagl'indiani, 26 de setiembre de 1877, sobre un ataque sufrido por colonos piamonteses en la colonia Tortugas, de esta última provincia.

${ }^{42}$ Cf. Immigrazione (Memoria del sig. Dillon), Diario y Episodi dell'emigrazione. En: L'Operaio Italiano, 9, 14 y 19 de agosto de 1877. 
Bartolomé Mitre. ${ }^{43}$ Esta identificación provocó incluso una clausura durante un mes de ese año, mientras que su director, el otrora sacerdote Enrique Romero Jiménez, un expatriado luego de la caída de la Primera República española, debió refugiarse en Montevideo. ${ }^{44}$ Más tarde, cuando la ley fue sancionada, El Correo circulaba con normalidad, manteniendo sus fuertes críticas al gobierno, que recién menguarían al año siguiente, con la reconciliación entre las principales fuerzas políticas porteñas.

Entretanto, las críticas a Avellaneda que se vinculaban con la inmigración apuntaban fundamentalmente a la impericia del gobierno para advertir las características de la crisis económica que se estaba viviendo y a su desidia para combatirla. Es así como abundaban los relatos sobre situaciones de inmigrantes arribados al país que no podían hallar trabajo y quedaban desamparados, ansiando el regreso a España, pero sin recursos para concretarlo. ${ }^{45} \mathrm{Ni}$ el debate de la ley ni su definitiva aprobación merecieron menciones en las páginas de $\mathrm{El}$ Correo Español. Sin embargo, pocas semanas después se hacía eco de la información transmitida por La Tribuna, según la cual se estaba gestando el plan de creación de una compañía particular que, aprovechando los beneficios de la nueva ley, instalaría doscientos agricultores españoles en un terreno situado en las márgenes del río Negro. La reacción de El Correo estaba a tono con su prédica, ya que apuntaba a que los vascos y cántabros que presuntamente integrarían el contingente, no hallarían más que decepciones, dado que el gobierno no respetaba las garantías ni defendía la propiedad. ${ }^{46}$

Por último, The Standard of River Plate News, el principal vocero de la colectividad británica, era el decano de los periódicos de ese tipo

\footnotetext{
${ }^{43}$ Ver por ejemplo Pérfidas insinuaciones y ¡Derrota del juez Demaría!. En El Correo Español, 10 y 22 de octubre de 1876.

${ }^{44}$ Reaparición del Correo Español, en Ibidem, 3 de agosto de 1876.

${ }^{45}$ Inmigración, Cuestión séria, La emigración europea, e Inmigración y miseria. En Ibidem, 30 de agosto, 8 y 11 de octubre y 4 de noviembre de 1876 .

${ }^{46}$ Colonias españolas. En Ibidem, 22 de octubre de 1876.
} 
y, según declaraba, el primero publicado en lengua inglesa en todo el hemisferio sur, ya que había iniciado sus ediciones en 1862. Dirigido por los hermanos Michael y Edward Mulhall, The Standard fue uno de los medios de prensa más atentos a los debates de la ley en 1875-76. Su interés se vinculaba sobre todo con los posibles emprendimientos en el sur del país que tuvieran como protagonistas a integrantes de dicha colectividad. Pero también con los riesgos que correrían las que ya estaban en marcha, como la colonia galesa de Chubut, en caso de no obtenerse garantías legislativas. ${ }^{47}$ Además, numerosas firmas vinculadas con el negocio de la emigración (bancos, compañías de navegación, compañías colonizadoras, agencias inmobiliarias, empresas ferroviarias y tranviarias) eran habituales anunciantes en su portada. La ley de 1876, según The Standard, constituía un serio intento de avanzar en la colonización y de consolidar las zonas de frontera, por lo que tanto la inmigración como las exportaciones hallarían nuevas oportunidades a partir de su sanción. ${ }^{48}$

Por su parte, el impacto de las principales disposiciones de la ley sobre las tendencias del flujo inmigratorio sería limitado durante la década siguiente a su sanción. Diversos fracasos del Departamento de Inmigración durante el resto del período de Avellaneda, en buena medida atribuibles a las limitaciones de su presupuesto y a la multiplicidad de sus atribuciones, llevaron a un reordenamiento de la agencia una vez que Roca asumió la presidencia. El Comisario General, Juan Dillon, fue sucedido por Samuel Navarro, quien, a diferencia de su antecesor, era un decidido partidario de la inmigración espontánea. ${ }^{49}$

${ }^{47}$ Ver The Welsh colony - Serious loss by fire - Fatal boat expedition - An Indian alarm, The land question of the Welsh colony y The Chubut colony - Distribution of land grants. En The Standard and River Plate News, 4, 6, 21 y 31 de octubre de 1876.

${ }^{48}$ The Standard también se hacía eco de las experiencias colonizadoras exitosas de otras colectividades en la región pampeana. Cf. por ejemplo The Danish colony of Tandil y Colonies in Entre Ríos, 31 de octubre y 1 de noviembre de 1876.

${ }^{49}$ DEPARTAMENTO GENERAL DE INMIGRAGIÓN. Memoria correspondiente al sexenio presidencial del Teniente General D. Julio A. Roca. Buenos Aires: Imprenta de "La Universidad", 1886, p. 5-6. Esto sin perjuicio de que algunos integrantes de la dirigencia política siguieran abo- 
Las funciones de la Dirección de Tierras y Colonias fueron separadas de las del Departamento y el intento de privilegiar a la inmigración con destino a las colonias nacionales fue abandonado, no sólo por las dificultades que presentaban estas últimas, sino porque otros sectores de la economía, como el transporte ferroviario, los puertos y la construcción urbana requerían una ingente cantidad de mano de obra. ${ }^{50}$

La superación de la crisis de mediados de la década de 1870 y la sostenida expansión de los años siguientes permitieron una recuperación de la corriente inmigratoria que alcanzaría nuevas marcas: de 41 mil inmigrantes ingresados en promedio en el quinquenio 1876-1880 se pasó a 70 mil en 1881-1885, sin necesidad de una intervención del Estado tan marcada como la que preveía el texto legislativo. Tampoco se modificaron sensiblemente las procedencias nacionales, al menos hasta 1887 (cuadro 2). Los italianos siguieron predominando con claridad durante esos años, alcanzándose incluso el récord de porcentaje de toda la serie en 1885, con el 78,8\% de los ingresados al país. La expansión agrícola y urbana de la Argentina seguía encontrando su principal reserva de mano de obra en la península itálica, aunque, dentro de ésta, se podía advertir una presencia cada vez mayor de los meridionales.

Sin embargo, asistimos a un importante cambio en 1888-1889, cuando el gobierno del presidente Miguel Juárez Celman decidió intervenir abiertamente en el flujo migratorio mediante el subsidio masi-

gando en esos años por la inmigración dirigida. Un ejemplo de ello en ZEBALLOS, Estanislao. Ley de estrangeros. Proyecto presentado al Congreso Argentino por... Buenos Aires: Imprenta de Jacobo Peuser, 1883, especialmente Títulos II, III y IV.

${ }^{50}$ Inclusive los principales proyectos de inmigración planificada, finalmente desechados, no correspondieron durante esa etapa a lo previsto en la ley sino a otros dos tipos. Por un lado, las grandes obras públicas que requerían trabajadores inmigrantes, como la construcción de la nueva ciudad de La Plata. Para estos emprendimientos no se requerían familias sino hombres solos, que además eran destinados a las áreas urbanas y no a las rurales, como prescribía la ley. Por el otro, las propuestas de empresas particulares, como el Lloyd Ítalo-Platense o el Lloyd Norte Alemán. En general, estos proyectos consistían en la introducción de una cantidad determinada de inmigrantes por año, sin especificación de su ulterior destino en la Argentina, a cambio de una suma a pagar por el Estado o bien de exenciones de derechos aduaneros para la importación de mercancías. Un detalle de los proyectos en Ibidem, pp.13-36, 87-139. 
vo de los viajes y la ampliación de las funciones de las agencias de propaganda en Europa. Durante ese bienio el Estado argentino financió aproximadamente 150 mil pasajes, lo cual constituye la cifra más alta de todo el ciclo histórico de la inmigración en el país. ${ }^{51}$ Como hemos visto, el adelanto de sumas para pasajes había sido incluido en la ley de 1876 como uno de los instrumentos estatales para la atracción de las familias inmigrantes. Su uso en gran escala a finales de la década de 1880 formaba parte de un programa económico más amplio, que recurría al aumento en el gasto público como una vía para acelerar el progreso. ${ }^{52}$ Es decir que se acudía a un instrumento pensado para un período de contracción de la economía (mediados de la década de 1870) durante una fase expansiva de la misma (fines de la década siguiente). Esta aparente contradicción puede explicarse por los temores que despertaba en Argentina la adopción de una política más agresiva de captación de inmigrantes europeos por parte de Brasil, y en particular del Estado de São Paulo, debido a la abolición de la esclavitud. ${ }^{53}$

Un objetivo secundario que se perseguía con el subsidio de pasajes en el caso argentino era el de diversificar el origen nacional de la inmigración, disminuyendo en lo posible la fuerte presencia italiana. Como

${ }^{51}$ Los fondos asignados por el Estado a la inmigración durante ese bienio fueron también, en términos relativos, los más altos de la historia. Baste mencionar que la suma gastada en pasajes subsidiados en 1889 (aproximadamente 5,5 millones de pesos moneda nacional) superaba a todo el presupuesto de inmigración de los años 1880-1888 sumados. A eso cabría agregar otros 300 mil pesos asignados a las oficinas de información en Europa, una cantidad que asimismo era mayor que todo lo gastado en inmigración en cualquier año, hasta 1887 inclusive. ALSINA, Juan. La inmigración europea..., op.cit., p. 123.

52 Sobre otras medidas que implicaban una expansión del gasto público durante la gestión juarista, expresión del optimismo reinante hasta la contracción de fines de 1889, cf. GERCHUNOFF, Pablo; ROCCHI, Fernando; ROSSI, Gastón. Desorden y progreso. Las crisis económicas argentinas (1870-1905). Buenos Aires: Edhasa, 2008, p. 92-97.

${ }^{53}$ El Estado de São Paulo comenzó a distribuir pasajes subsidiados para colonos europeos que se instalarían en las fazendas en 1884, es decir algunos años antes de la definitiva abolición de la esclavitud. La cuestión era seguida con gran interés por los funcionarios argentinos, debido a los posibles efectos sobre el flujo de emigrantes hacia el país. Cf. por ejemplo COMISARIO GENERAL DE INMIGRACIÓN. Informe del... sobre el pasaje de privilejio. Buenos Aires: Imprenta de Los Tiempos, 1884, p. 10 y ss. 
se advierte en el cuadro 2, ello fue fugazmente logrado, ya que durante el bienio 1888-1889 no sólo se elevó mucho el total de inmigrantes recibidos, sino también el porcentaje correspondiente a españoles y a terceras procedencias. Grupos nacionales hasta entonces casi inexistentes en el panorama de las colectividades establecidas, como los holandeses o los belgas, o regionales dentro de la península ibérica, como los andaluces o los murcianos, fueron beneficiados con esa distribución de pasajes que llegó a un abrupto final con la crisis de $1890 .{ }^{54}$ Se trata por lo tanto del único momento en que los italianos quedan por debajo de la mitad de los ingresos durante la segunda mitad del siglo XIX.

Otros aspectos en los cuales fue ampliándose la intervención oficial, en cumplimiento de la ley de inmigración y colonización o de leyes anteriores, fueron los relativos al desembarco, alojamiento y colocación de los recién llegados. La cuestión del desembarco de los inmigrantes había sido motivo de preocupación ya desde 1871. La Comisión Central de Inmigración elaboró en ese año un reglamento, que ordenaba el establecimiento de un empleado del organismo en el pontón en el que se realizaba la visita sanitaria de los buques de pasajeros que entrarían en el puerto. El empleado debía informar a los inmigrantes de los beneficios que por ley estipulaba la Argentina y entregar a cada uno un boleto numerado que les permitía acceder al desembarco gratuito o bien al trasbordo, en caso de que continuaran viaje por los ríos Paraná o Uruguay. Con ello se trataba de evitar la acción de los patrones de embarcaciones que trataban de lucrar con el traslado de los inmigrantes hasta el puerto. ${ }^{55}$ En el cuadro 3 podemos

${ }^{54}$ José Moya ha mostrado como la inmigración andaluza de ese bienio, que ejemplifica con los malagueños, no procedía de cadenas parentales o paisanas, sino de los subsidios de pasajes. Esto la diferenciaría de los movimientos de otras regiones de España, como Galicia, y limitaría su continuidad luego de la crisis de 1890. Cf. Primos y extranjeros. La inmigración española en Buenos Aires, 1850-1930. Buenos Aires: Emecé, 2004, p. 86-89.

${ }^{55}$ Cf. Proyecto de reglamento para el desembarco de los inmigrantes, en COMISIÓN CENTRAL DE INMIGRACIÓN. Informe de la... 1870, op.cit., p. 97-100; su actualización en la década de 1880 en DEPARTAMENTO GENERAL DE INMIGRACIÓN. Memoria correspondiente al sexenio..., op.cit., p. 10. 
observar que el porcentaje de los desembarcados con este sistema fue incrementándose con rapidez, alcanzando claramente el máximo en el bienio final de la década de 1880, en consonancia con la actitud más intervencionista por parte del Estado que hemos advertido en cuanto al pago de los pasajes.

La siguiente columna refleja la proporción de quienes fueron alojados en los hoteles de inmigrantes durante el máximo de cinco días siguientes al arribo. También se trata de cifras crecientes, con máximo a fines de la década de 1880, pero que siempre dejan afuera a más de un cuarenta por ciento de los inmigrantes. Esto se debe a que no todos ellos apelaban a este beneficio: el carácter espontáneo de gran parte de la emigración hacía que quienes llegaban al país contaran a menudo con familiares o paisanos que los estaban esperando en el puerto o que les habían indicado un domicilio adonde dirigirse luego del arribo. ${ }^{56}$ En cualquier caso, es muy significativo que en 1888-89, por lo que se deduce de estos guarismos, aproximadamente cien mil inmigrantes anuales eran alojados en esas instalaciones, por cuenta de la Nación. ${ }^{57}$

Los datos de la última columna son algo más complicados para interpretar, ya que suman dos situaciones diferentes: la de quienes accedían a su primer trabajo a través de la oficina de empleo que funcionaba en el propio alojamiento y la de quienes obtenían el pasaje gratuito, terrestre o fluvial, hasta la localidad en la que se instalarían. Tales beneficios se combinaban en muchos casos, pero no siempre. Sea como fuere, las proporciones de los favorecidos también son ascendentes en este rubro, incluso luego de la crisis de 1890, aunque desde entonces y hasta el final de la serie se aplican sobre una cantidad total de ingresos notoriamente disminuida. Según Juan Alsina, quien sucedió

${ }^{56}$ Sobre este aspecto, DEVOTO, Fernando. Historia de la inmigración en la Argentina. Buenos Aires: Sudamericana, 2003, p. 79-80.

${ }^{57}$ La inversión que se hizo en este rubro durante 1889 también fue enorme: 750.000 pesos moneda nacional, una cifra superior a todo el presupuesto de inmigración de 1888 y aproximadamente el triple del promedio de dicho presupuesto de 1880-1887. Cf. ALSINA, Juan. La inmigración europea..., op.cit., p. 123. 
en ese año a Navarro como director del Departamento, esta repartición siguió por un cierto tiempo colocando o internando inmigrantes en cumplimiento de contratos celebrados con anterioridad, lo que podría explicar dicho incremento en el porcentaje. ${ }^{58}$

En suma, el Estado argentino fue logrando, en un tiempo relativamente corto, una cobertura significativa de aquellos servicios de desembarco, alojamiento, manutención, internación y colocación de inmigrantes a los que se comprometía de acuerdo con la legislación aprobada por el Congreso. Las razones por las que esa cobertura no fue todavía más amplia no deben buscarse en las deficiencias de las agencias que debían ocuparse de tales servicios, sino más bien en la gravitación de los mecanismos micro-sociales a través de los cuales aquéllos arribaban al país y obtenían su primer alojamiento y empleo. ${ }^{59}$ Diferente se presentaba el panorama en el otro capítulo de esa legislación, es decir en lo referido a la influencia de la colonización oficial como sistema de atracción e integración de los inmigrantes. Hacia mediados de la década de 1890 las colonias establecidas y en funcionamiento en los territorios nacionales eran muy pocas: dos en Misiones, una en Formosa, tres en Chaco, tres en Río Negro y dos en Chubut. A ello se debe agregar que algunas existían ya antes de la aprobación de la ley de 1876 y que otras no respondían al modelo colonizador fijado en la misma, sino a soluciones ad hoc a las que había recurrido el Estado ante las dificultades que se fueron presentando. ${ }^{60}$

${ }^{58}$ Sobre los internados y colocados por el Departamento luego de 1890 cf. ALSINA, Juan. La inmigración en el primer siglo de la independencia. Buenos Aires: Felipe Alsina editor, 1910, p. 34-40.

${ }^{59}$ Cabe agregar en este punto que la mejora de los contactos marítimos con Europa durante la década de 1880 permitió implementar el sistema de los "pasajes de llamada", por el cual los inmigrantes establecidos en el país podían financiar el traslado de sus parientes. Un cálculo de 1893 estimaba que los pasajes comprados en ese año con tal sistema superaban los veinte mil, lo cual representaría nada menos que la cuarta parte del total de los ingresos. La proporción real, sin embargo, debió ser mayor, si tenemos en cuenta que un pasaje de llamada podía comprender a varios miembros de una misma familia que viajaran juntos. Cf. DEPARTAMENTO GENERAL DE INMIGRACIÓN. Memoria del... correspondiente al año 1893. Buenos Aires: Imprenta Coni, 1894, p. 7-8.

${ }^{60}$ ALSINA, Juan. La inmigración europea..., op.cit., p. 315-327. 
Un segundo grupo de colonias funcionaba en jurisdicción de las provincias, sea porque éstas hubiesen cedido tierras o porque el Estado nacional hubiese acudido en su auxilio para evitar que se extinguiesen. En cualquier caso, se trataba de sólo dos emprendimientos en Entre Ríos y cuatro en Córdoba. Por otro lado, la cantidad de familias europeas instaladas en ambos tipos de colonias probablemente no sobrepasaba el millar, lo cual era casi ínfimo si comparamos con las magnitudes del movimiento inmigratorio del período. Resulta claro por lo tanto que algunos de los pronósticos formulados durante el debate de la ley estaban lejos de cumplirse, como el que advertía sobre las decenas de miles de empleados que formarían la burocracia del Departamento General de Inmigración una vez que el sistema de las colonias nacionales estuviera en pleno funcionamiento, o el que auguraba una extensión a la Patagonia y al Chaco de los positivos efectos alcanzados con la colonización en Santa Fe. Desde luego, eso no significa que la integración de los inmigrantes en la actividad agrícola no continuase por otras vías, como el arrendamiento, la aparcería y eventualmente la compra-venta de tierras entre particulares, o la colonización a través de empresas.

\section{Conclusiones}

La ley de inmigración y colonización constituyó uno de las principales realizaciones de la ideología agrarista decimonónica que confiaba en los positivos efectos a obtener para la economía y la sociedad argentinas mediante la combinación de ambos factores. El Estado podía desempeñar un rol protagónico en la puesta en práctica de dicha combinación, como en cierto modo preanunciaban algunos de los artículos de la constitución nacional y como demostrarían las experiencias pioneras de las provincias litoraleñas. Los objetivos perseguidos por el gobierno de Avellaneda estaban en consonancia con tales expectativas, aunque a ellas se sumaban las urgencias derivadas de la primera crisis severa que afectó a la economía nacional en la era post-Caseros y el clima de creciente intervención estatal en materia de inmigración que alcanzaba a los países vecinos. Precisamente, los debates parlamentarios habrían de revelar el clivaje entre esa línea intervencionista -con 
antecedentes en la propia Argentina- y la que presentaba a la inmigración espontánea y a la colonización privada como las opciones más adecuadas, cuyo principal vocero fue el senador Oroño.

Triunfante la primera y aprobada la ley, las dificultades de su implementación habrían de revelarse de inmediato, sobre todo por lo que se refiere a la articulación ideal entre la promoción y selección de la inmigración, de una parte, y la instalación de una estructura de colonias agrícolas administradas por el Estado nacional y localizadas en sitios agrestes o poco integrados, de la otra. El segundo término del binomio fue el que presentó los mayores impedimentos, pero ello no obstaculizó la rápida recuperación de la corriente inmigratoria desde comienzos de la década del ochenta. La secesión obrada por entonces entre las funciones del Departamento General de Inmigración y de la Dirección de Tierras y Colonias vendría a reconocer ese divorcio de hecho. En otros aspectos operativos la intervención estatal se mostraría mucho más eficaz, como por ejemplo en la recepción y albergue de los inmigrantes, en la recolección de ofertas de empleo, en el traslado de aquéllos hacia el interior y, hasta cierto punto, en la supervisión del accionar de las compañías de navegación.

Tales formas de intervención alcanzarían su punto más alto durante la presidencia de Juárez Celman, pese a que tradicionalmente la misma aparece caracterizada como un modelo de abstención ante el libre juego de las fuerzas del mercado. En un contexto de expansión económica, su gobierno apeló de manera decidida a instrumentos que habían sido diseñados durante una etapa de reflujo, en particular al subsidio de pasajes transatlánticos. Con ello logró alterar desde el Estado, probablemente por única vez en toda la historia de la inmigración en Argentina, algunos de los datos básicos de una corriente que seguía caracterizándose por el predominio de los mecanismos micro-sociales. La crisis de 1890-92 pondría punto final a esos arrestos intervencionistas, dejando tan mal recuerdo de ellos que, más allá de las propuestas de mayor selección y control que se plantearán de manera recurrente, 
la actitud liberal y de no injerencia en materia inmigratoria será la que prime durante las siguientes cuatro décadas.

\section{Bibliografía citada}

BERTAGNA, Federica. La stampa italiana in Argentina. Roma: Donzelli, 2009.

DE MARCO, Miguel Ángel. Historia del periodismo argentino. Desde los orígenes hasta el Centenario de Mayo, Buenos Aires: Editorial de la Universidad Católica Argentina, 2006.

DEVOTO, Fernando. Políticas migratorias argentinas y flujo de población europea (1876-1925). En ----, Estudios sobre la emigración italiana a la Argentina en la segunda mitad del siglo XIX. Napoli: Edizioni Scientifiche Italiane, 1992, p. 45-68.

DEVOTO, Fernando. El revés de la trama: políticas migratorias y prácticas administrativas en la Argentina (1919-1949). En Desarrollo Económico, Buenos Aires, n. 162, p. 281-304, julio-setiembre de 2001.

DEVOTO, Fernando. Historia de la inmigración en la Argentina. Buenos Aires: Sudamericana, 2003.

DEVOTO, Fernando y OTERO, Hernán, Veinte años después: una lectura sobre el pluralismo cultural y la historia nacional en la historiografia argentina. En Estudios Migratorios Latinoamericanos, n. 50, 2003, p. 181-227.

DJENDEREDJIAN, Julio. Gringos en las pampas. Inmigrantes y colonos en el campo argentino. Buenos Aires: Sudamericana, 2008.

DJENDEREDJIAN, Julio; BEARZOTTI, Sílcora; MARTIRÉN, Juan Luis. Expansión agrícola y colonización en la segunda mitad del siglo XIX, T. 6 de la Historia del capitalismo agrario pampeano. Buenos Aires: Teseo-Universidad de Belgrano, 2010.

FERRERES, Orlando. Dos siglos de economía argentina (1810-2004). Buenos Aires: Fundación Norte y Sur, 2004.

FRONTERA, Carlos. Las ideas sobre inmigración en el debate de la ley $\mathrm{N}^{\circ}$ 817 y en los periódicos de la época. En Revista de Historia del Derecho, Buenos Aires, n. 16, 1988, p. 287-319.

GERCHUNOFF, Pablo; ROCGHI, Fernando; ROSSI, Gastón. Desorden y progreso. Las crisis económicas argentinas (1870-1905). Buenos Aires: 
Edhasa, 2008.

GONÇALVES, Paulo Cesar. Mercadores de braços. Riqueza e acumulação na organização da emigração europeia para o Novo Mundo. São Paulo: Alameda, 2012.

HALPERÍN DONGHI, Tulio. José Hernández y sus mundos. Buenos Aires: Sudamericana-Instituto Torcuato Di Tella, 1985.

HALPERÍN DONGHI, Tulio. ¿Para qué la inmigración? Ideología y política inmigratoria en Argentina (1810-1914). En ----, El espejo de la historia. Problemas argentinos y perspectivas latinoamericanas. Buenos Aires: Sudamericana, 1987, p. 192-238.

MÍGUEZ, Eduardo. Historia económica de la Argentina. De la conquista a la crisis de 1930. Buenos Aires: Sudamericana, 2008.

MOYA, José Carlos. Primos y extranjeros. La inmigración española en Buenos Aires, 1850-1930. Buenos Aires: Emecé, 2004.

NOVICK, Susana. Política y población. Argentina 1870-1989. Buenos Aires: Centro Editor de América Latina, 1992, 2 vols.

NOVICK, Susana. Políticas migratorias en la Argentina. En OTEIZA, Enrique; NOVICK, Susana; ARUJ, Roberto. Inmigración y discriminación. Políticas y discursos. Buenos Aires: Prometeo, 2000.

NOVICK, Susana. Migración y políticas en Argentina: tres leyes para un país extenso (1876-2000). En Cuadernos del Pensamiento Crítico Latinoamericano. Buenos Aires: CLACSO, 2008.

PÉREZ, Mariana (selección y estudio preliminar). Inmigración y colonización. Los debates parlamentarios del siglo XIX. Los Polvorines: Universidad Nacional de General Sarmiento, 2012.

SEYFERTH, Giralda. Colonização, imigração e a questão racial no Brasil. En Revista USP. São Paulo, n. 53, p. 117-149, março - maio 2002.

STABILI, Maria Rosaria, Las políticas inmigratorias de los gobiernos chilenos desde la segunda mitad del siglo pasado hasta la década de 1920. En Estudios Migratorios Latinoamericanos, Buenos Aires, n. 2, p. 181-202, abril 1986.

Recebido: 16/05/2017 - Aprovado: 03/10/2017 